\title{
GROWTH LAYER PATTERNS IN ARCTOCEPHALUS AUSTRALIS CANINE TEETH: EVALUATION OF TECHNIQUES FOR AGE DETERMINATION
}

\author{
Daniza Molina-Schiller ${ }^{1,2}$ and Maria Cristina Pinedo ${ }^{2}$
}

\begin{abstract}
A total of 75 canine teeth from 27 A. australis (13 males and 14 females) were examined. The animals were found dead from 1977 to 1997 on the coast of Rio Grande do Sul, Brazil. Growth Layer Groups (GLGs) in each canine were compared and examined for age determination using four techniques. These four techniques were evaluated according to the visible number of GLGs in dentine and cementum (techniques 2, 3 and 4) or external rings (technique 1). Technique 4 (decalcified and stained thin section) was the best technique for age determination in A. australis, as it showed the highest conspicuousness of the growth layers (GLGs and accessory layers) in dentine and cementum (especially in old exemplars with pulp cavity closed). Technique 3 (half- tooth etched in 5\% formic acid and rubbed with graphite powder) was selected as second best, and recommended for use in dentine counts up to 10 GLGs in males and 6 GLGs in females. Technique 1 (external rings on canine root) offered easy readings until approximately the seventh ring, beyond which misreadings in age determination occurred. Technique 2 (thick unstained and undecalcified sections) presented limitations for obtaining sections of the same thickness compromising a good reading of the GLGs. This in turn could influence the resolution of the growth layers, as the GLGs reading in dentine and cementum were more difficult in this technique than in technique 4.

Resumen - Un total de 75 dientes caninos de 27 A. australis (13 machos y 14 hembras) fueron examinados. Los animales fueron encontrados muertos en la costa de Rio Grande do Sul - Brasil desde 1977 a 1997. Grupos de Capas de Crecimiento (GLGs) fueron comparados y examinados en cada canino para determinación de edad usando 4 técnicas. Estas cuatro técnicas fueron evaluadas de acuerdo al número visible de GLGs en la dentina y cemento (técnicas 2, 3 y 4) o anillos externos (técnica 1). La técnica 4 (secciones finas descalcificadas y teñidas) fue la mejor técnica para determinación de edad en A. australis, ya que presentó mayor conspicuidad de las capas de crecimiento (GLGs y capas accesorias) en la dentina y cemento (especialmente en ejemplares adultos con cavidad pulpar cerrada). Técnica 3 (dientes bisectados, descalcificados con ácido fórmico 5\% y cubiertos con grafito) fue seleccionada en segundo lugar y recomendamos que el uso de la dentina debería ser hasta 10 GLGs en machos y 6 GLGs en hembras. Técnica 1 (anillos externos sobre la raíz del canino) ofrece lecturas fáciles hasta aproximadamente el séptimo anillo, después de esto las lecturas pueden llevar a errores en la estimación de la edad. Técnica 2 (secciones gruesas sin descalcificar y no teñidas) presentaron limitaciones para obtener secciones de la misma espesura comprometiendo una buena lectura de las GLGs, probablemente esto influyo en la resolución de las capas de crecimiento, porque las lecturas de las GLGs en la dentina y cemento fueron más difíciles que en la técnica 4 .
\end{abstract}

Key words: age determination, Arctocephalus australis, Brazil, GLGs, growth layers, teeth, pinnipeds.

\section{Introduction}

Age determination in any animal population is a fundamental tool for understanding the biology of individuals and population dynamics, and provides useful information for conservation and management procedures.

A Growth Layer Group (GLG), by definition, is not necessarily an annual layer, but rather a repeating pattern that can be counted (Hohn et al., 1989). Thus, as a generic term a GLG must be defined whenever used (Perrin and Myrick, 1980).

Different techniques have been used for age determination in pinniped teeth (e.g., Scheffer, 1950; Laws, 1952, 1953, 1958, 1962; Pierce and Kajimura, 1980; Scheffer and Myrick, 1980; Bowen et al., 1983; Schiavini et al., 1988, 1992; McCann, 1993; Crespo et al., 1994; Stewart et al. ,1996; Amano et al., 2000; Dickie and Dawson, 2003).

Readings of GLGs in dentine and cementum of canine and post-canine teeth of pinnipeds of known age have been performed for some species, e.g., Callorhinus ursinus (Scheffer, 1950; Kubota et al., 1961; Yagi et al., 1963; Anas, 1970), Phoca vitulina (Mansfield and Fisher, 1960), Zalophus californianus (Odell, 1975; Lowry and Folk, 1990),
Arctocephalus gazella (Payne, 1978; Bengtson, 1988), Phoca groenlandica (Bowen et al., 1983), Halichoerus grypus (Mansfield, 1991), Otaria flavescens (Rosas et al., 1993), Mirounga angustirostris (Klevezal and Stewart, 1994), and Arctocephalus pusillus pusillus (Oosthuizen,1997).

To date, GLG deposition patterns have not been established for A. australis. Payne (1978) observed in A. gazella the equivalence of a GLG for every year of age, based on eleven known-age individuals. Also, this same equivalence was observed in Otaria flavescens by Rosas (1989), based on a known-age individual kept in captivity.

Different techniques have been used for age determination using canines of $A$. australis (e.g., number of external rings on canine root; polished and unstained thick sections; halftooth etched in 5\% formic acid and rubbed with graphite powder and decalcified and stained thin sections) by Schiavini et al. (1988, 1992) and Crespo et al. (1994). However, comparative studies among the different techniques using the same canines have not been performed for GLG readings in dentine and cementum, or the description of deposition pattern of GLGs.

For selecting which is the more suitable technique for each species, first it is necessary to evaluate GLG readability

\footnotetext{
${ }^{1}$ Current address: Universidade Federal do Rio Grande do Sul, Pós-Graduação em Ecologia. Av. Bento Gonçalves 9500. Cx. Postal 15007, Porto Alegre, RS 91540-000 Brazil. E-mail: daniza@marinemammals.cl.

${ }^{2}$ Fundação Universidade Federal do Rio Grande (FURG), Departamento de Oceanografia. C.P. 474, Rio Grande, RS $96201-900$ Brazil.
} 
based on conspicuousness of boundary layers, consistency and continuity of layers along the length of the whole tooth section. Results of these evaluations will permit the standardization of the methodology for use in future comparative studies.

The goals of the present study were to compare four known age determination techniques to characterize growth layer patterns in canines of $A$. australis and to select the best technique for age determination, based on conspicuousness of GLGs.

\section{Material and Methods}

A total of 75 canine teeth extracted from 27 A. australis (13 males and 14 females) were examined. The animals were founded dead from 1977 to 1997 along the coast of Rio Grande do Sul, Brazil. This coast has been surveyed as part of a long-term beach monitoring program conducted by the Laboratory of Marine Mammals and Marine Turtles (LMM) of the Oceanography Department of the Fundação Universidade Federal do Rio Grande (FURG), Brazil. The material collected was deposited at LMM.

Four techniques were used for age determination (external rings on canine root; thick unstained and undecalcified sections; half-tooth etched in 5\% formic acid and rubbed with graphite powder and decalcified and stained thin sections). For each technique the growth layer patterns were characterized. Two GLG readings were conducted by the first author with intervals of at least two weeks. When differences were found, a third reading was performed and selected, under the assumption that skill and accuracy increased with time.

The term Growth Layer Group (GLG) was defined in this study as a group of incremental opaque and translucid growth layers present in dentine or cementum, which are deposited annually (Perrin and Myrick, 1980). An accessory layer was defined as any single layered component of a GLG which is discernible from adjacent layers in a hard tissue (Scheffer and Myrick, 1980). For external rings on canine root, each GLG consisted of a ridge (elevation) and a valley (depression) and each ring was assumed to represent one year of age (Perrin and Myrick, 1980). An annual GLG deposition pattern was adopted in $A$. australis by Schiavini et al. (1992) and Crespo et al. (1994). In this study we also assumed that the layering pattern represented one year's growth and the term annual GLG was applied.

The four compared techniques were:

\section{External rings on canine root (Technique 1)}

This method was described for the first time in C. ursinus by Scheffer (1950) and applied to A. australis by Schiavini et al. $(1988,1992)$ and Crespo et al. (1994). This technique consists of the direct counting of number of rings visible on the external root, which is related to GLGs. Here, only upper canines were used and each ring was assumed to represent one year of age. External rings on canine root were observed directly and under reflected light with a dissecting microscope at $8 \mathrm{X}$ magnification. The distinction of the external rings was accentuated by the application of graphite powder on the surface of the root, according to Pierce and Kajimura (1980).

\section{Thick unstained and undecalcified sections (Technique 2)}

Although this technique has been used in several species of marine mammals (Scheffer and Myrick, 1980), modifications have been carried out for some species to obtain the best resolution in the GLGs. In Páez (1989) and Schiavini et al. $(1988,1992)$, teeth were cut and ground with sandpaper (100 to 600 gradation) to produce unstained thick sections of $200-500 \mathrm{~mm}$. The readings were made under transmitted light. Mansfield (1991) used thin sections of approximately $150 \mathrm{~mm}$, stored in alcohol-glycerine solution, and readings were also made under transmitted light using polarizing filters.

In this study, upper canine sections from mid-longitudinal axis were obtained with a low-speed diamond circular saw (Buehler-Isomet). These sections were cut following the dental line with anterior-posterior orientation of the tooth. Thicknesses of these sections were of approximately $1.1 \mathrm{~mm}$ (minimum thickness obtained with a $15 \mathrm{~cm}$ diamond blade) and were not ground with sandpaper (to minimize mistakes in the uniformity of the thickness). Prior to being read, sections were stored in a solution (alcohol $70 \%$ and glycerine 2:1) for two months. After that, they were mounted on glass slides in pure glycerine, and subsequently the dentine and cementum GLGs were counted under transmitted light using polarizing filters through a stereoscopic dissecting microscope at 840X magnification.

Half-tooth etched in 5\% formic acid and rubbed with graphite powder (Technique 3)

This technique was originally described for odontocetos by Pierce and Kajimura (1980) and later modified to be used in canine teeth of O. flavescens (Rosas et al., 1993; Crespo et al., 1994), and A. australis (Schiavini et al., 1988; 1992).

Upper canines were bisected longitudinally with a lowspeed diamond circular saw (Buehler-Isomet). Sections were obtained on anterior-posterior orientation of the tooth and etched in $250 \mathrm{ml} 5 \%$ formic acid for 1.5-4 hours, depending on the size of the tooth. The half-tooth was then rinsed in running water for 24 hours and air-dried. The GLG readings were enhanced by rubbing the surface of the tooth with graphite powder as suggested by Crespo et al. (1994). GLGs in the dentine and cementum were analyzed under reflected light with a dissecting microscope at 8-40X magnification.

\section{Decalcified and stained thin sections (Technique 4)}

This technique was widely used in delphinid cetaceans (Perrin and Myrick, 1980; Hohn et al., 1989), and later applied to A. australis by Schiavini et al. (1992) and Crespo et al. (1994).

Central longitudinal sections around 3 to $5 \mathrm{~mm}$ in thickness were made on anterior - posterior orientation of the tooth 
using a low-speed diamond circular saw (Buehler-Isomet). These sections were decalcified with $R D O \AA$, a fast commercial decalcifier, composed of a mixture of acids. Decalcification time ranged from 1 to $30 \mathrm{~h}$, depending on the size of the tooth. The sections were considered ready when flexible, bending in the center, and then were rinsed in running water for 24 hours. From each tooth, thin sections 25 to $30 \mu \mathrm{m}$ thick were obtained using a $\mathrm{CO}_{2}$ freezing microtome. Then two or three on-center sections were selected according to the criterion of conspicuousness of boundary layers, consistency and continuity of layers along the length of the whole tooth section (Hohn et al., 1989; Pinedo and Hohn, 2000). Sections were stained in $250 \mathrm{ml}$ Harris's haematoxylin for $5 \mathrm{~min}$ and rinsed in running water for 24 hours to eliminate excess of stain (Molina and Oporto, 1993). Tooth sections were immersed in $50 \%$ and $100 \%$ glycerine for 30 minutes, to dehydrate and were mounted on glass slides in pure glycerine (Myrick et al., 1983; Hohn et al., 1989). GLGs in the dentine and cementum of the teeth were read using a compound microscope 10-50X under transmitted light. Only on-center and "close-to-center" sections were used for GLG readings. "Close-to-center" sections were defined according to Pinedo and Hohn (2000) (i.e., apex of GLGs round and with $60 \%$ of the whole extension of the pulp cavity visible). The first GLG was defined according to the models proposed for Tursiops truncatus by Hohn (1980) and without access to biological data. In dentine, four measurements were taken perpendicularly to the bottom of the neonatal line using a micrometer ocular in a compound microscope at 100X with transmitted light. The neonatal line was used as guideline to measure the first GLG. The second and third GLGs were measured using the previous GLG as reference. In addition, the first accessory layer was measured. Cementum GLGs were counted, but not measured.

The individuals were chosen from a larger sample at random $(n=239)$ among males and females, and without previous knowledge of sex and total length (MolinaSchiller, 2000). Canines were removed from the upper and lower jaws of each skull. In three of four techniques where it was necessary to cut the tooth, one upper canine was bisected to be used in techniques 2 and 3 , and the other upper canine was used in the technique 4.

The canines were curved in two directions. The lower canines were more curved than upper canines and the pulp cavity closed sooner than in the upper canines, being a limitation in the identification of the last GLGs present in dentine and cementum (Molina-Schiller, 2000). Difficulties to obtain good cuts in lower canines of A. gazella and A. pusillus were earlier mentioned by McCann (1993) and Oosthuizen (1997).

Due to these difficulties, only upper canines were used here for characterizing GLGs. This curvature was seen as a difficulty for obtaining "on-center" cut sections according to the approach described by Hohn et al. (1989) (e.g., cuts along the mid-longitudinal plane, which show the apices of the layers, which are pointed rather than round, and the entire extension of the opening of the pulp cavity).

\section{Comparison of the techniques}

The four techniques were evaluated in 27 individuals and 75 teeth, according to the visible GLG number as well as the simplicity of the technique. The resolution of each GLG was evaluated according to the conspicuousness of boundary layers, consistency and continuity of layers along the whole length of the tooth section in the dentine and cementum (Hohn et al., 1989). Univariate tests of significance were made for statistic differences among GLG numbers in these four techniques (Zar, 1984).

\section{Results}

\section{Technique 1 - External rings on canine root}

External rings on upper canine roots were more visible in males than in females (Figure 1). Each ring consisted of a ridge (elevation) and a valley (depression). Identification of the first external ring was not easy and females usually presented the greatest difficulty in this reading (Figure 1). From the teeth sample used $(n=27)$ rings in this technique could only be counted up to approximately the seventh ring. Beyond that, rings were not visible or poorly visible. Eleven individuals presented visible rings, three specimens did not present visible rings and eleven individuals $<1$ year of age did not present visible rings on canine root (Table 1). The main disadvantage observed was due to the closure of the pulp cavity together with the increment of cementum the canine root in older individuals. This can cause misreadings in age determination and result in underestimates of age (Table 1).

\section{Technique 2 - Thick unstained and undecalcified sections}

GLGs were visible in the dentine and cementum (Table 1). In dentine, the neonatal line was formed by a thin translucent layer. The first GLG begins after the neonatal line, constituted by a thick opaque layer and thin translucent layer. The following GLGs were similar to the first, but as the pulp cavity decreased, the layers were reduced in thickness. However, it was not always easy to identify the limit of each GLG, since the boundary of the translucent layer was not always conspicuous (Figure 2a). In each GLG, around 11 to 13 accessory layers (narrow layers) were observed. These layers were constituted by a thin opaque layer and a thin translucent layer (Figure 2b). In cementum, GLGs were more conspicuous than in dentine and each GLG was formed by a thick translucent layer followed by a thin opaque layer. Accessory layers were not observed (Figure $2 b$ ).

Technique 3 - Half-tooth etched in 5\% formic acid and rubbed with graphite powder

Conspicuous GLGs were present in dentine and cementum. In dentine, the neonatal line and the growth layers were very well defined, offering no difficulties for identifying and reading GLGs. In dentine, the neonatal line was constituted by a thin translucent layer followed by a thin opaque layer. 


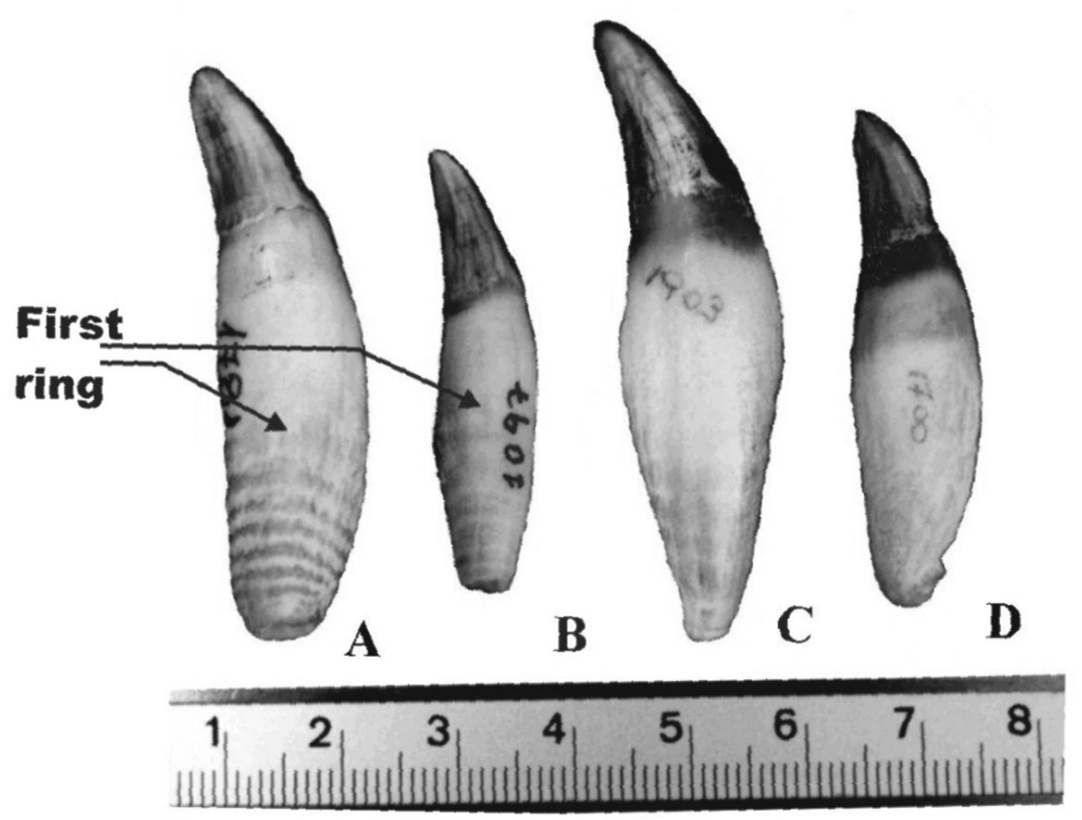

Figure 1. External rings on upper canine root (technique 1) of A. australis. Male with 7 rings (A), female with 7 rings (B), male with 10 rings $(C)$ and female with 11 rings $(D)$.

A

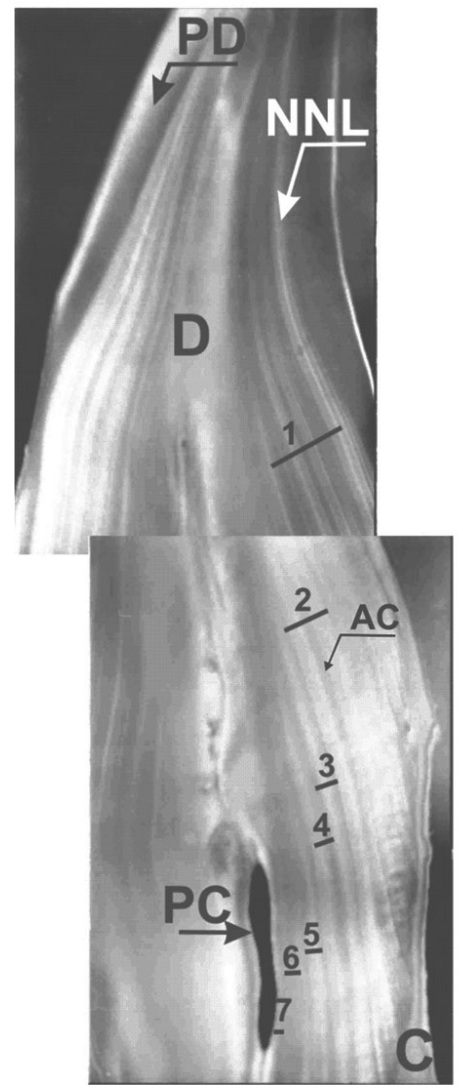

B

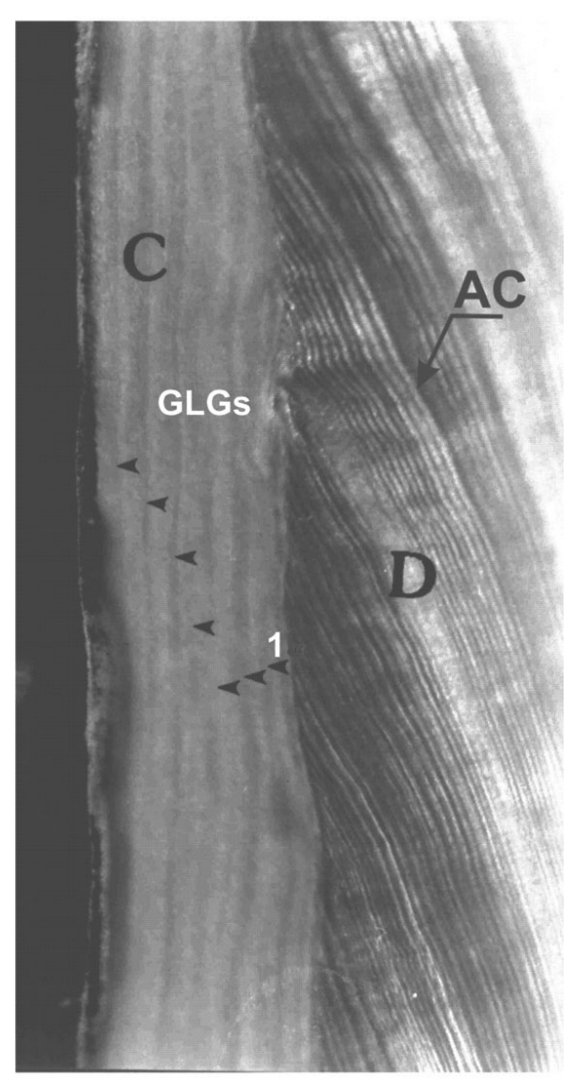

Figure 2. Longitudinal thick unstained and undecalcified sections (technique 2) (outside of the center) of an upper canine of $A$. australis (LMM 1444). Dentine with 7 GLGs (A), cementum with 7 GLGs (B). (NNL) neonatal line, (C) cementum, (AC) central accessory layers, (PC) pulp cavity, (PD) prenatal dentine. Each black arrow indicates one GLG in cementum. 
Table 1. GLGs obtained from four techniques in dentine and cementum for males and females of $A$. australis.

\begin{tabular}{|c|c|c|c|c|c|c|c|c|}
\hline \multirow{3}{*}{$\begin{array}{c}\text { LMM } \\
\text { ACESSION NUMBER }\end{array}$} & \multirow{3}{*}{ SEX } & \multicolumn{7}{|c|}{ AGE ESTIMATION TECHNIQUES } \\
\hline & & \multirow{2}{*}{$\frac{1}{\text { RINGS }}$} & \multicolumn{2}{|c|}{2} & \multicolumn{2}{|c|}{3} & \multicolumn{2}{|c|}{4} \\
\hline & & & $\mathrm{D}$ & $\mathrm{C}$ & $\mathrm{D}$ & $\mathrm{C}$ & $\mathrm{D}$ & C \\
\hline 107 & $\sigma^{\prime \prime}$ & $0^{*}$ & 0 & $\mathrm{nv}$ & 0 & $\mathrm{nv}$ & 0 & nv \\
\hline 630 & $\sigma^{\prime \prime}$ & $0^{*}$ & $\mathrm{nv}$ & $\mathrm{nv}$ & 0 & nv & 0 & nv \\
\hline 663 & $\sigma^{\prime \prime}$ & 6 & 7 & 6 & 7 & 6 & 5 & 6 \\
\hline 732 & $\sigma$ & 8 & 7 & 6 & 9 & 7 & $\mathrm{nv}$ & 7 \\
\hline 1091 & $\sigma^{\prime}$ & 3 & 2 & $\mathrm{nv}$ & 3 & nv & 3 & nv \\
\hline 1120 & $\sigma^{\prime}$ & 1 & 1 & $\mathrm{nv}$ & 1 & $\mathrm{nv}$ & 1 & nv \\
\hline 1326 & $\sigma^{*}$ & $0^{*}$ & 0 & $\mathrm{nv}$ & 0 & $\mathrm{nv}$ & 0 & $\mathrm{nv}$ \\
\hline 1444 & $\sigma$ & 7 & 7 & 7 & 7 & 6 & 6 & 6 \\
\hline 1470 & $\sigma^{\prime \prime}$ & $0^{*}$ & 0 & $\mathrm{nv}$ & 0 & $\mathrm{nv}$ & 0 & $\mathrm{nv}$ \\
\hline 1731 & $\sigma^{\prime}$ & 3 & $\mathrm{nv}$ & $\mathrm{nv}$ & 3 & $\mathrm{nv}$ & 3 & $\mathrm{nv}$ \\
\hline 1868 & $\sigma^{\prime \prime}$ & 1 & 1 & $\mathrm{nv}$ & 1 & $\mathrm{nv}$ & 1 & $\mathrm{nv}$ \\
\hline 1869 & $\sigma^{\prime \prime}$ & 0 & 1 & $\mathrm{nv}$ & 1 & $\mathrm{nv}$ & 1 & $\mathrm{nv}$ \\
\hline 1892 & $\sigma^{\circ}$ & $0^{*}$ & 0 & $\mathrm{nv}$ & 0 & $\mathrm{nv}$ & 0 & $\mathrm{nv}$ \\
\hline 111 & 우 & $0^{*}$ & 0 & $\mathrm{nv}$ & 0 & $\mathrm{nv}$ & 0 & $\mathrm{nv}$ \\
\hline 491 & 우 & $\mathrm{nv}$ & $\mathrm{nv}$ & 11 & 9 & $\mathrm{nv}$ & $\mathrm{nv}$ & 16 \\
\hline 616 & 우 & $0^{*}$ & 0 & $\mathrm{nv}$ & 0 & $\mathrm{nv}$ & 0 & $\mathrm{nv}$ \\
\hline 711 & 우 & $\mathrm{nv}$ & 10 & 11 & 8 & $\mathrm{nv}$ & $\mathrm{nv}$ & 11 \\
\hline 836 & 오 & $\mathrm{nv}$ & 7 & 7 & 7 & $\mathrm{nv}$ & $\mathrm{nv}$ & 7 \\
\hline 1097 & 우 & 7 & $\mathrm{nv}$ & $\mathrm{nv}$ & 7 & $\mathrm{nv}$ & 5 & 7 \\
\hline 1530 & 우 & 0 & 1 & $\mathrm{nv}$ & 1 & $\mathrm{nv}$ & 1 & nv \\
\hline 1343 & 오 & $0^{*}$ & 0 & $\mathrm{nv}$ & 0 & $\mathrm{nv}$ & 0 & $\mathrm{nv}$ \\
\hline 1450 & 우 & $0^{*}$ & 0 & $\mathrm{nv}$ & 0 & $\mathrm{nv}$ & 0 & $\mathrm{nv}$ \\
\hline 1564 & 오 & $0^{*}$ & 0 & $\mathrm{nv}$ & 0 & $\mathrm{nv}$ & 0 & $\mathrm{nv}$ \\
\hline 1567 & 우 & $0^{*}$ & 0 & $\mathrm{nv}$ & 0 & $\mathrm{nv}$ & 0 & $\mathrm{nv}$ \\
\hline 1516 & 우 & 6 & $\mathrm{nv}$ & $\mathrm{nv}$ & 6 & $\mathrm{nv}$ & 4 & $\mathrm{nv}$ \\
\hline 1692 & 우 & 2 & $\mathrm{nv}$ & $\mathrm{nv}$ & 2 & $\mathrm{nv}$ & 2 & nv \\
\hline 1697 & 우 & 6 & $\mathrm{nv}$ & $\mathrm{nv}$ & 6 & $\mathrm{nv}$ & 4 & 6 \\
\hline \multicolumn{3}{|c|}{$\%$ Coincidence dentine } & 76 & & 85 & & 70 & \\
\hline \multicolumn{3}{|c|}{$\%$ Coincidente cementum } & & 50 & & 60 & & 89 \\
\hline
\end{tabular}

(LMM) Laboratory of Marine Mammals and Marine Turtles; techniques: (1) external rings on canine root, (2) thick unstained and undecalcified sections, (3) half-tooth etched in 5\% formic acid and rubbed with graphite powder, (4) decalcified and stained thin sections; (nv) not visible GLG, (D) dentine, (C) cementum; $\left(^{*}\right)$ individual $<1$ year old.

Each GLG was constituted by a light layer observed as a narrow ridge (elevation), following by a dark layer observed as a wide valley (depression) (Figure 3a). Each GLG also presented 10 to 12 accessory layers (Figure $3 b$ ).

Cementum GLGs were conspicuous; each annual layer consisted of a thick translucent layer followed by a thin opaque layer. Cementum GLGs were not observed as elevations and depressions, and accessory layers were not observed (Figure 3b). In general, males presented conspicuous GLGs in the cementum, while in females GLGs were not always conspicuous and in some individuals $(n=6)$ they were absent (Table 1$)$.

\section{Technique 4-Decalcified and stained thin sections}

In dentine, the neonatal line was observed as a narrow translucent layer followed of a narrow opaque layer. The conspicuousness of the neonatal line allowed using it as point of reference in the measurement of the first GLGs (Figure 4). The first GLG was formed by an opaque layer followed by a translucent (or unstainable) layer. The 
boundary of the first GLG was not always easy to identify, due to the difference in intensity of the coloration between the first and second GLGs. In all analyzed individuals a conspicuous accessory layer was observed in the first GLG (Figure 4), present in most cases in the center of this GLG. This accessory layer could be misread with the limit between the first and second GLGs, when this limit appears diffuse. The mean width of the first GLG was approximately $1608.52 \mu \mathrm{m}$ and the mean distance between the central accessory layer and the neonatal line was of approximately $776.67 \mu \mathrm{m}$ (Table 2; Figure 4). The second GLG was narrower than the first, with a mean width of approximately $1114.12 \mu \mathrm{m}$ (equivalent to $69.26 \%$ of the width of the previous GLG) (Table 2; Figure 4). In the second GLG the opaque and translucent layers were better defined than in the first GLG and the identification of the limit between the second and the third GLG was usually detected by the intense coloration of the opaque layer (Figure 4). The third GLG was measured similarly to the previous GLGs and the mean width was approximately $921.33 \mu \mathrm{m}$ (equivalent to $57.28 \%$ of first GLG) (Table 2).

Cementum GLGs were observed as a thin opaque layer followed by a thick translucent layer. In all translucent layers, 6 to 8 narrow layers were observed. In males the GLGs were more conspicuous (Figure 5a) than in females (Figure 5b). However, while in some females $(n=3)$ and males $(n=5)$ the GLGs were absent or not visible, they were visible in dentine (Table 1).

\section{Comparison of the four techniques}

The numbers of GLGs obtained in the dentine and/or cementum through the four techniques were not always the same (Table 1). The univariate test of significance did not show significant differences ( $p>0.05)$.

Technique 1 (external rings on canine root) was considered simple and economic, offering easy readings until approximately the seventh ring. After that, the rings were not visible or poorly visible and can cause misreadings in age determination and underestimate age (Table 1).

Technique 2 (thick unstained and undecalcified sections) presented limitations in obtaining sections of the same thickness, with the low speed diamond circular saw, compromising a good central cut and therefore a good conspicuousness in GLG readings in the dentine and cementum. This difficulty likely influenced the resolution of the growth layers, because the GLGs reading in dentine and cementum were more difficult than in technique 4 .

Technique 3 (half-tooth etched in 5\% formic acid and rubbed with graphite powder) was simple and fast developed and allowed GLG readings in dentine up to the closing of the pulp cavity which occurred approximately at 10 GLGs in males and at 6 GLGs in females. Beyond these ages or closeness of the pulp cavity, the readings were made in cementum (Table 1).

The GLG readings in cementum presented limitations, especially in females, as GLGs were not always visible. The GLG readings in cementum were more difficult than in technique 4 .
Technique 4 (decalcified and stained thin sections) was the more expensive, but showed the highest conspicuousness in GLG readings of dentine and cementum, especially for identifying the first three GLGs, or in the estimate of age of old exemplars with closed pulp cavity.

In dentine, techniques 2 and 3 presented highest percentages of coincidence in GLGs readings, $76 \%$ and $85 \%$, respectively (Table 1). Technique 4 presented $70 \%$ of coincidence; however GLGs were always more conspicuous and easy to read, giving a higher confidence to identify GLGs when compared with the other techniques, when the objective was to know the identification pattern of the first two GLGs (Figure 4).

In cementum, technique 4 presented the highest percentage $(89 \%)$ of coincidence of GLGs (Table 1$)$. This technique was considered more reliable for estimating age in old individuals or when the growth layers are not always visible in the dentine (Figures 5a-b).

Anomalies were represented by pulp stones and mineralization interference. The pulp stones were observed in techniques 3 and 4 , as nodules containing concentric rings along the entire dentine of the canine tooth (Figure $6 a)$. These pulp stones were present in 17 males and 3 females with 6 to 13 GLGs (Molina-Schiller, 2000).

The mineralization interference was observed in technique 3 , as an irregularity in the development pattern of the dentine layers, extending from the apex to the limit of the pulp cavity (Figure 6b). These anomalies were observed in 2 males (6 and 11 GLGs) (Molina-Schiller, 2000). Mineralization was not observed in the root. However, there was an individual that presented undulations in the limit of the pulp cavity, making difficult the identification of the last GLGs (Figures 3a; 6b).

\section{Discussion}

The GLG patterns in dentine of A. australis from this study was similar to those previously described for the species (Schiavini et al., 1992; Crespo et al., 1994), and to those of other pinnipeds, e.g., A. gazella (Payne, 1978; McCann, 1993; Bengtson, 1988), A. pusillus pusillus (Oosthuizen,1997), C. ursinus (Anas, 1970), H. grypus (Mansfield, 1991), M. angustirostris (Klevezal and Stewart, 1994), O. flavescens (Rosas et al., 1993) and P. groenlandica (Bowen et al., 1983). Conspicuous and central accessory layers identified in first GLG of the dentine (techniques 2, 3 and 4) have been previously observed in Tursiops truncatus (Hohn, 1980), Inia geoffrensis (da Silva, 1995), Cephalorhynchus eutropia (Molina and Reyes 1996) and Pontoporia blainvillei (Pinedo and Hohn, 2000).

The identification of the rings on canine root (technique 1) was easier in males and females with less than seven rings, due to closure of the pulp cavity together with the increment of cementum the canine root in older individuals. These findings are similar to those described elsewhere for A. australis (Schiavini et al., 1992; Crespo et al., 1994), C. ursinus (Anas, 1970) and A. gazella (Payne, 1978; McCann, 1993). 
A

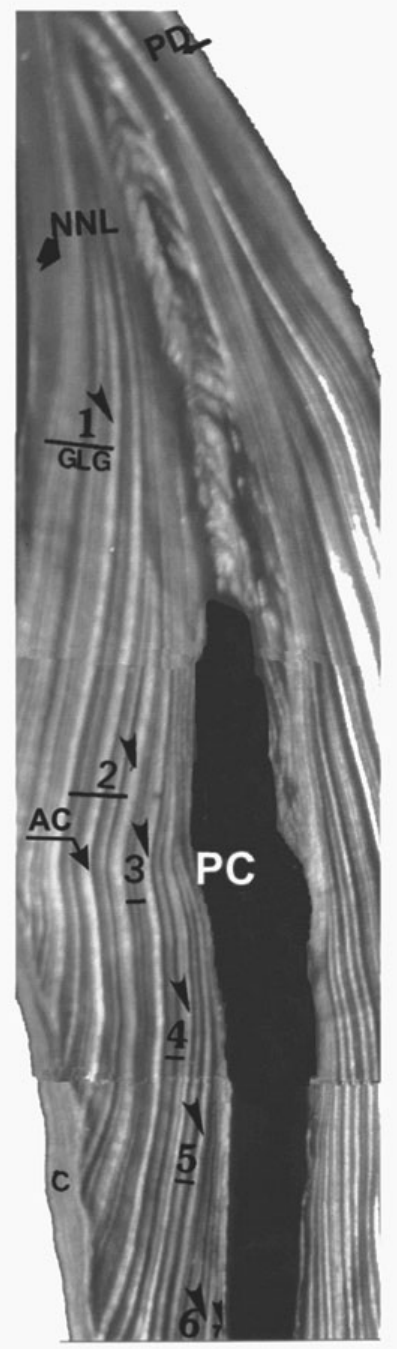

B

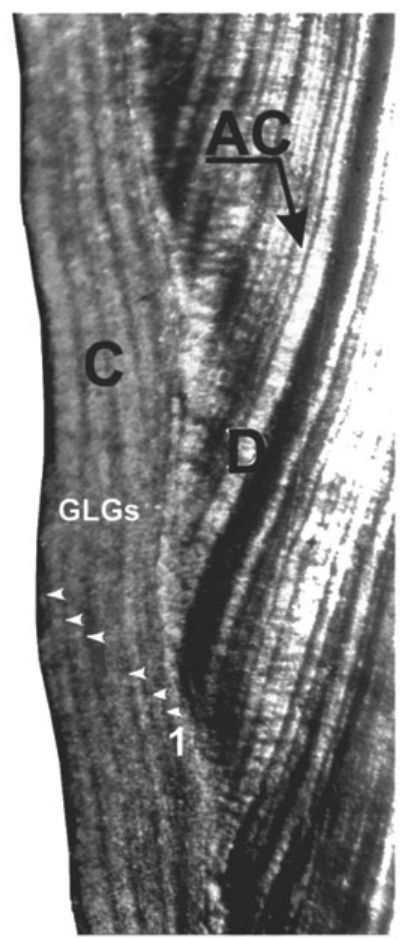

Figure 3. Half-tooth etched in 5\% formic acid and rubbed with graphite powder (technique 3) of an upper canine of A. australis (LMM 1444). Dentine with 7 GLGs (A), cementum with 6 GLGs (B). (NNL) neonatal line, (C) cementum, (AC) central accessory layers, (PC) pulp cavity, (PD) prenatal dentine. Each white arrow indicates one GLG in cementum.

Table 2. Measurements $(\mu \mathrm{m})$ of the first three GLGs and of the accessory layers (AC) (taken in the first GLG) obtained in males and female dentines of $A$. australis.

\begin{tabular}{lcccccc}
\hline \hline DENTINE & $\mathrm{n}$ & MEAN & MINIMUM & MAXIMUM & SD & C V (\%) \\
\hline \hline $\mathrm{AC}$ & 27 & 776.67 & 520.00 & 1110.00 & 123.57 & 15.91 \\
$1^{\text {st }}$ GLG & 27 & 1608.52 & 1160.00 & 1850.00 & 150.61 & 9.36 \\
$2^{\text {nd }}$ GLG & 17 & 1114.12 & 1000.00 & 1400.00 & 104.23 & 9.36 \\
$3^{\text {rd }}$ GLG & 15 & 921.33 & 850.00 & 1200.00 & 82.10 & 8.91 \\
\hline \hline
\end{tabular}

All measures were taken on "on-center" cuts. 


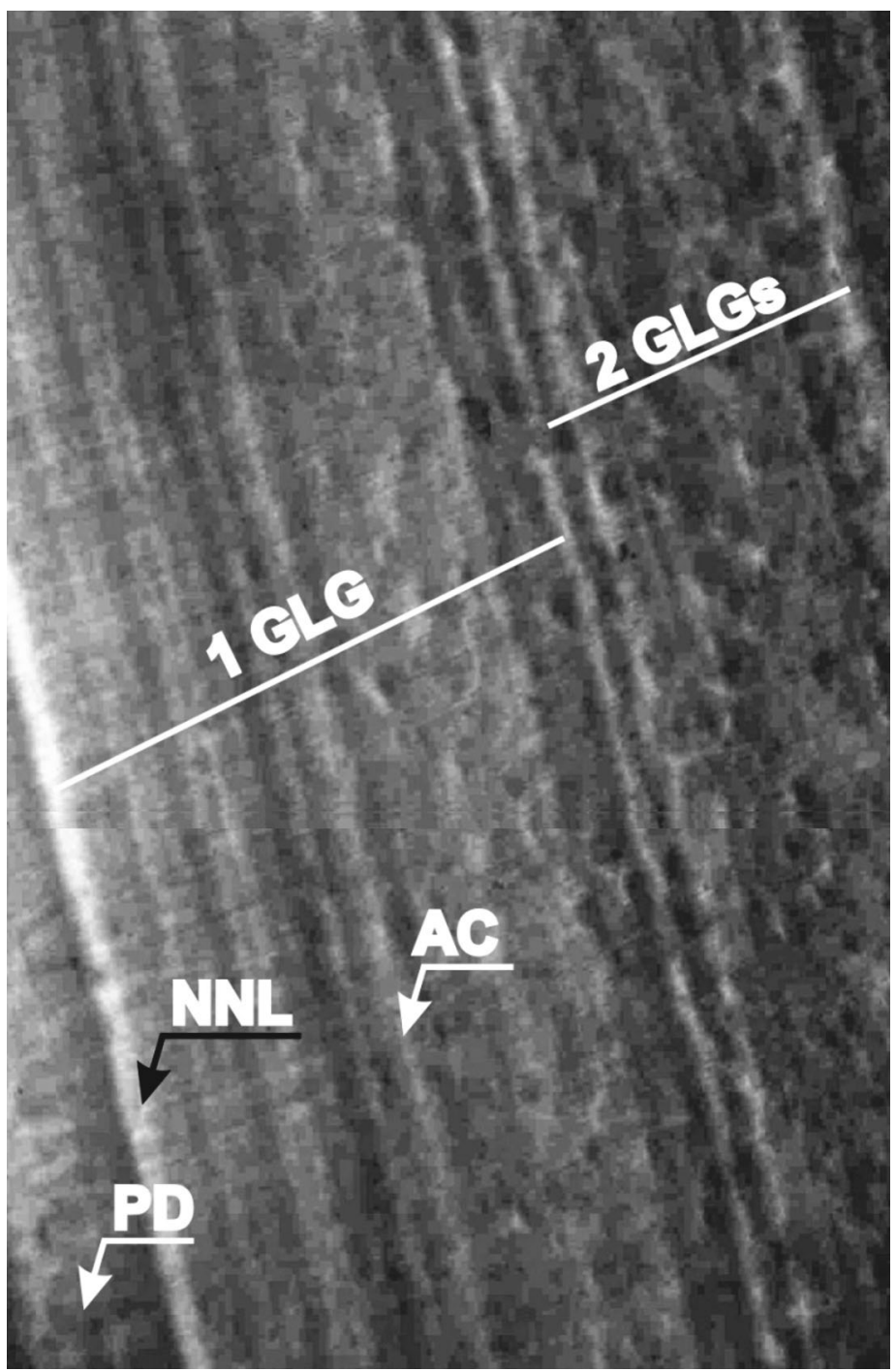

Figure 4. Longitudinal decalcified and stained thin section (technique 4) (on-center sections) of an upper canine of A. australis (LMM 1444). (NNL) neonatal line, (AC) central accessory layers, (PD) prenatal dentine.

Although measurements of GLGs obtained in this study were useful guidelines for detecting limits of GLGs in dentine, they should be used with caution in animals from other study areas along the distribution range of $A$. australis, since skull differences might occur due to geographical variation (Oliveira et al., 1999). The true limit of GLGs can only be determined when the animals are marked with tetracycline or other markers (annual extractions) (Hohn et al., 1989). However, measures and relative sizes of GLGs are useful as guidelines, reducing the probability of interpreting accessory layers as limits of GLGs (Hohn et al., 1989; Pinedo and Hohn, 2000).

The GLGs observed in cementum of females were not always conspicuous. These differences could possibly be related with the degree of accuracy that each technique provides, and the degree of pulp cavity closure and the width of the cementum (Table
1). These differences could be also related to a possible simultaneous deposition of those two structures, as observed in Franciscan's teeth by Pinedo and Hohn (2000). A differential deposition or disturbance in the cementum deposition pattern in females of $A$. australis could be perhaps associated with the nutritional and physiologic demands associated with pregnancy and especially lactation, as has been suggested for Odobenus rosmarus rosmarus (Mansfield, 1958) and Phoca hispida (Stewart et al., 1996).

The presence of globular stones and interference in the mineralization in the same upper canine could indicate that the anomaly in the mineralization would be of systemic origin, as the type, pattern and age of the anomaly were similar (Lockyer, 1993).). It has been proposed that $A$. australis reaches the sexual maturity at 7 years of age (Bonner, 1981; Reijnders et al., 1993), coinciding with the age of emergence of those 
A

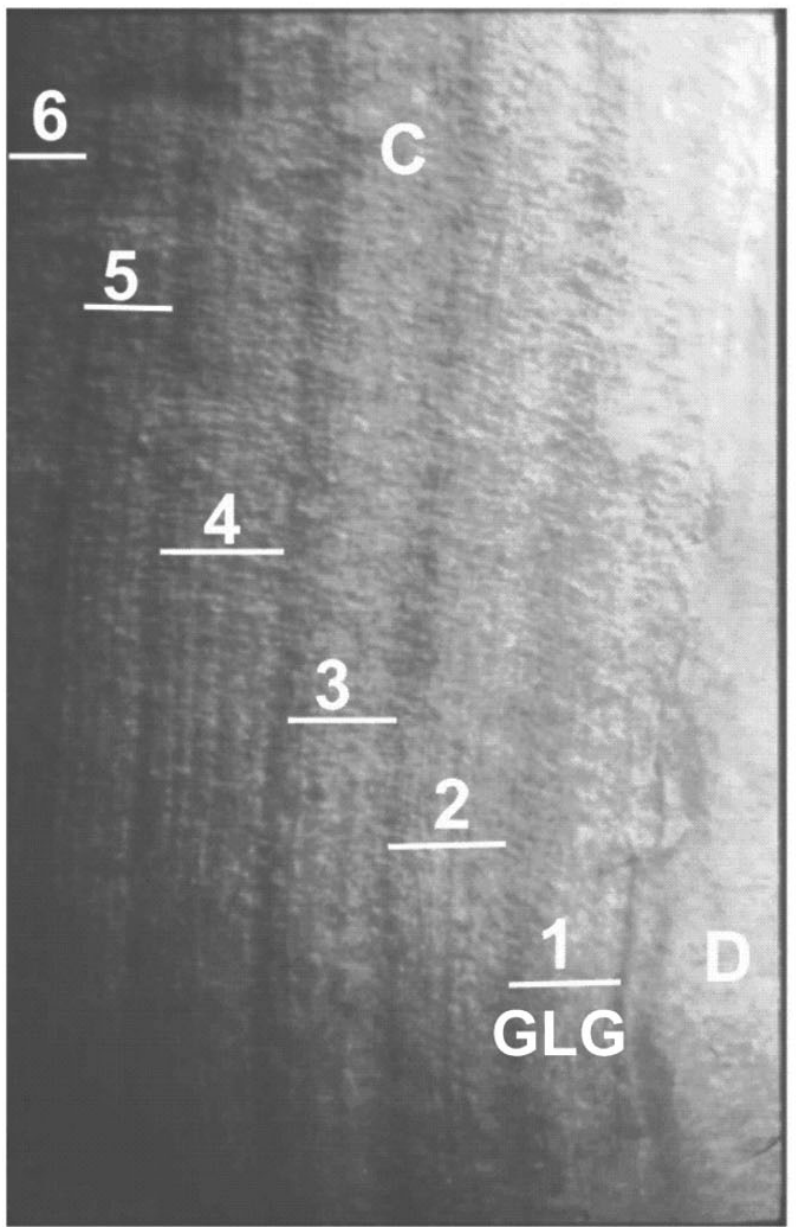

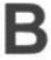

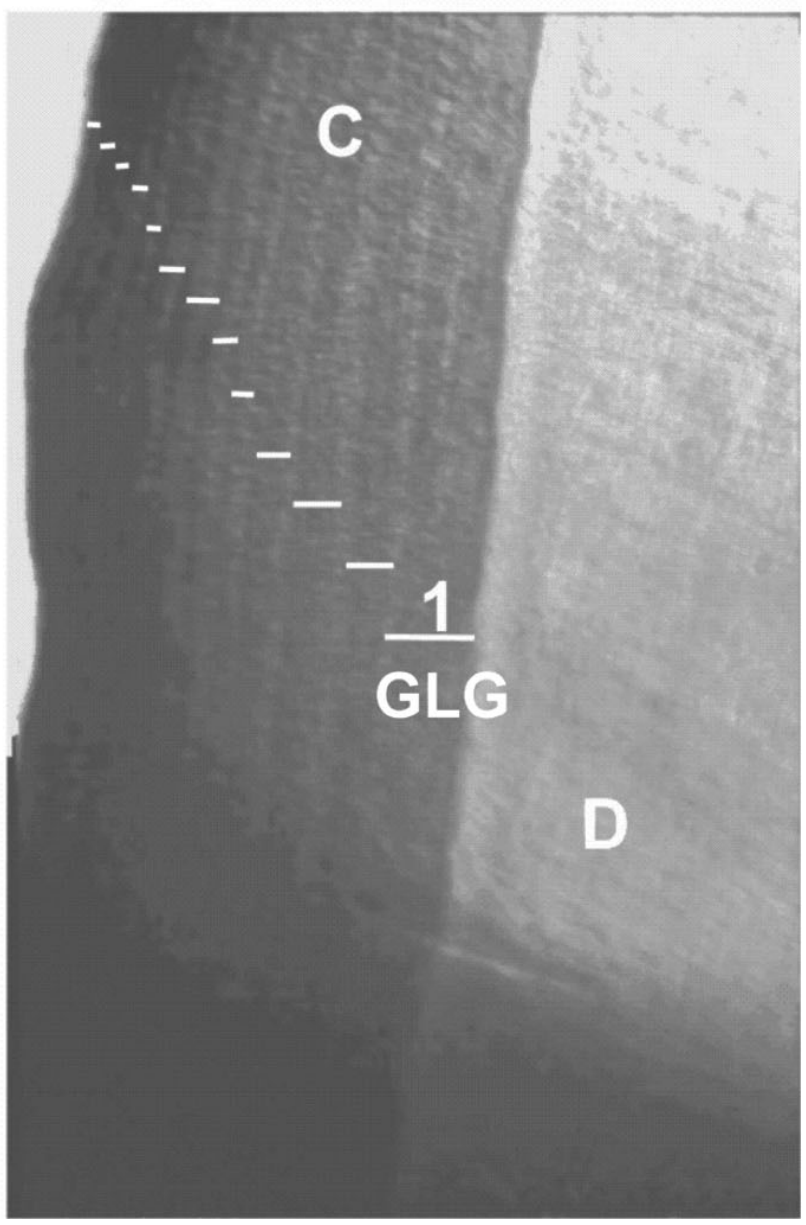

Figure 5. Longitudinal decalcified and stained thin section (technique 4) (on-center sections) of upper canines of $A$. australis. Male with 6 GLGs (LMM 1444) (A) and female with 13 GLGs (LMM 1132) (B). (D) dentine, (C) cementum.

globular stones observed in the present study. In Globicephala macrorhynchus, the globular stones in the dentine tend to be associated with the age of sexual maturity (Lockyer, 1993).

\section{Conclusions}

The evaluation of the four techniques according to the visible number of GLGs in dentine and cementum showed that technique 4 (decalcified and stained thin section) was the best for age determination, since it showed the highest conspicuousness of the first three growth layers (GLGs and accessory layers) in dentine and cementum (especially in old specimens with pulp cavity closed). Technique 3 (half- tooth etched in 5\% formic acid and rubbed with graphite powder) was selected as second best, as the GLGs were less conspicuousness in dentine and cementum as compared with Technique 4 . Technique 3 allowed GLGs readings in dentine up to the closing of the pulp cavity which occurred approximately at 10 GLGs in males and at 6 GLGs in females. Beyond these ages or closure of the pulp cavity, the readings were made in cementum, but in females the GLGs were not always visible or were poorly visible. Technique 1 (external rings on canine root) provided easy readings until approximately the seventh ring, beyond which misreadings could occur and result in underestimates of age due to closure of the pulp cavity. Technique 2 (thick unstained and undecalcified sections) can be used for readings dentine and cementum, but it presented restrictions for obtaining sections of the same thickness and probably influencing the resolution of the GLGs.

We recommend the use of standardized methodologies in age determination to allow for reliable comparative studies in different populations of $A$. australis. 

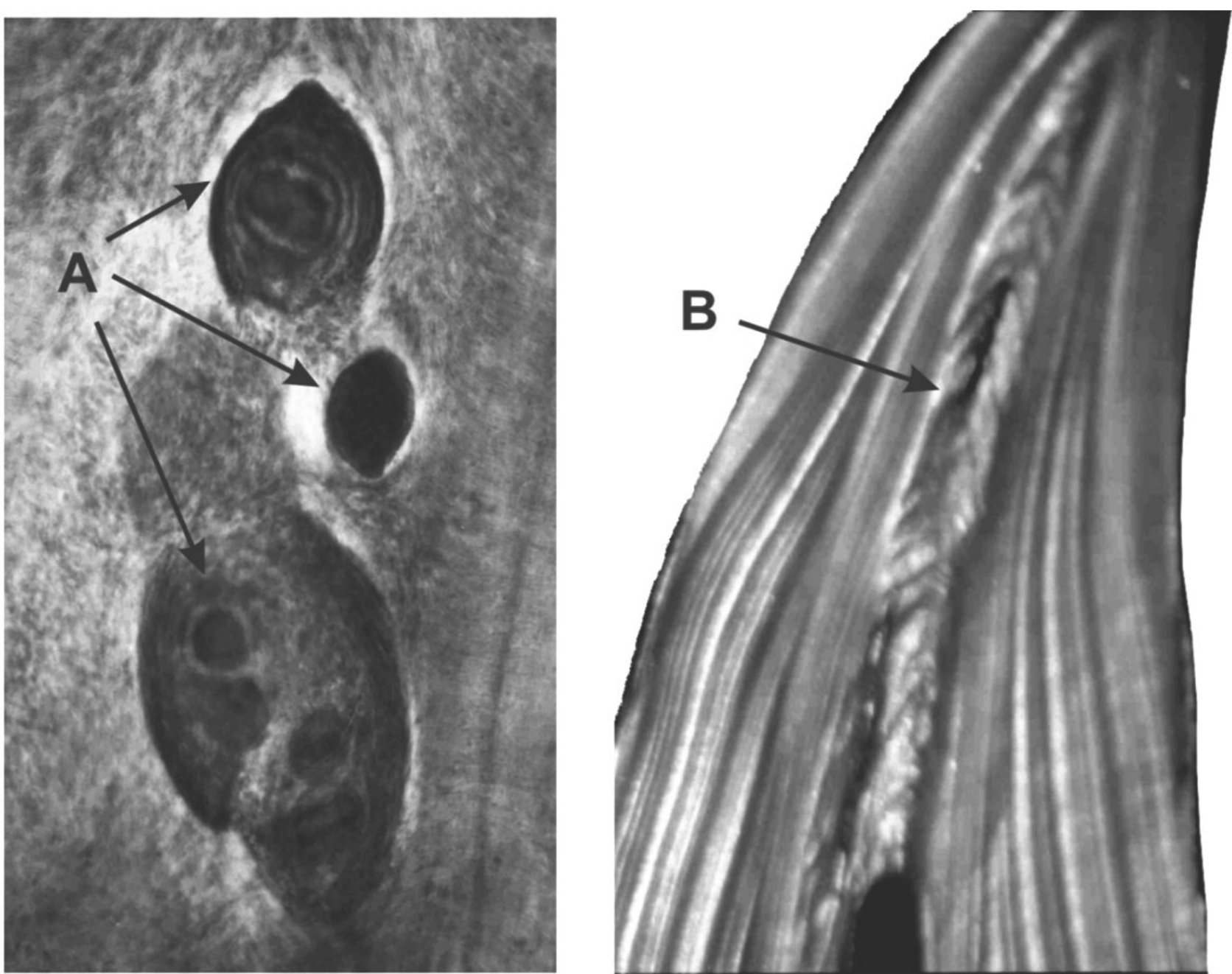

Figure 6. Anomalies dentinal of canines of A. australis. Pulp stones in female of 13 years old (LMM 1132) (A) and mineralization interference in male of 6 years old (LMM 1444) (B).

\section{Acknowledgements}

Thanks to all those involved in the fieldwork in Rio Grande, especially to André Barreto and Ana L. Andrade. This study was part of a Master Thesis of D. Molina-Schiller, which was supported by grants from CNPq (136348/96-3) and FAPERGS (96/60143.7). We thank Dr. Larissa Oliveira, Dr. Silvana Dans and Dr. Nelio Barros for reviewing the English and for their helpful comments on the manuscript.

\section{References}

Anas, R.E. (1970) Accuracy in assigning ages to fur seals. Journal of Wildlife Management 34: 844-852.

Amano, M., Miyazaki, N. and Petrov, A. (2000) Age determination and growth of Baikal seals (Phoca sibirica). Advances in Ecological Research. Vol. 31: 449-462.

Bengtson, J.L. (1988) Long-term trends in the foraging patterns of females Antartic fur seals at South Georgia. Pages 286-91 in Sahrhage, D. (Ed.) Antartic
Ocean and Resources Variability. Springer-Verlag, Berlin and Heidelberg.

Bonner, W.N. (1981) Southern Fur Seals, Arctocephalus (Geoffroy Saint-Hilaire and Cuvier, 1826). Pages 161-208 in Ridgway, S.H. and Harrison, R.J. (Eds) Handbook of Marine Mammals. Vol 1: The Walrus, Sea Lions, Fur Seals and Sea Otter. Academic Press, London.

Bowen, W.D., Sergeant, D.E. and Øritsland, T. (1983) Validation of age estimation in the harp seal, Phoca groenlandica, using dentinal annuli. Canadian Journal of Fisheries. Aquatic Sciences 40:1430-1441.

Crespo, E.A., Schiavini, A.C.M.G., Perez Macri, Reyes, L. and Dans. S. (1994) Estudios sobre determinación de edad en mamíferos marinos del Atlântico Sudoccidental. Pages 3155 in Anales IV Reunión de Trabajo de Especialistas en Mamíferos Acuáticos de América del Sur.

Da Silva, V. (1995) Age estimation of the amazon dolphin, Inia geoffrensis, using laminae in the teeth. Reports of the International Whaling Commission (Special Issue 16): 531-43.

Dickie, G.S. and Dawson, S.M. (2003) Age, growth, and reproduction in New Zealand fur seals. Marine Mammal Science 19(1): 173-185. 
Hohn, A.A. (1980) Age determination and age related factors in the teeth of Western North Atlantic bottlenose dolphins. The Scientific Reports of Whales Research Institute 32: 39-66.

Hohn, A.A., Scott, M.D., Wells, R.S., Sweeney, J.C. and Irvine, A.B. (1989) Growth layers in teeth from knownage, free-ranging bottlenose dolphins. Marine Mammal Science 5(4): 315-342.

Klevezal', G. and Stewart, B.S. (1994) Patterns and calibration of layering in tooth cementum of female northern elephant seal, Mirounga angustirostris. Journal of Mammalogy 75(2): 483-87.

Kubota, K.M.D., Nagasaki, A.D, Matsumoto, K. and Tsuboi, M. (1961) Histological studies on the growth layers in the maxillary canines of fur seals as an indicator of age. Part 1 . The teeth at the age of one to nine year. The Bulletin of Tokyo Medical and Dental University 8(3): 261-285.

Laws, R.M. (1952) A new method of age determination for mammals. Nature 169: 972-974.

Laws, R.M. (1953) A new method of age determination in mammals with special reference to the elephant seal (Mirounga leonina). Falkland Islands Dependencies Survey Scientific Reports 2: 1-11.

Laws, R.M. (1958) Growth rates and ages of crabeater seals, Lobodon carcinophagus. Proceedings of the Zoological Society of London 130: 275-88.

Laws, R.M. (1962) Age determination of pinnipeds with special reference to growth layers in the teeth. Zeitschrift für Saügetierkunde 27(3): 129-146.

Lockyer, C. (1993) A report on patterns of deposition of dentine and cementum in teeth of pilot whales, genus Globicephala. Reports of the International Whaling Commission (special issue 14): 137-63.

Lowry, M.S. and Folk, R.L. (1990) Sex determination of the California sea lion (Zalophus californianus) from canine teeth. Marine Mammal Science 6(1): 25-31.

Mansfield, A.W. (1958) The biology of the Atlantic walrus, Odobenus rosmarus rosmarus (Linnaeus) in the eastern Canadian Artic. Fisheries Research Board of Canada Manuscript Report Series in Biology 653. 146pp.

Mansfield, A.W. and Fisher, H.D. (1960) Age determination in the Harbour seal, Phoca vitulina $L$. Nature 186: 92-93.

Mansfield, A.W. (1991) Accuracy of age determination in the grey seal Halichoerus grypus of eastern Canada. Marine Mammal Science 7(1): 44-49.

McCann, T.S. (1993) Age determination. Pages 199-227 in Antarctic Seal Research Methods and Techniques. R.M.Laws Ed. Cambridge University Press.

Molina-Schiller, D.M. (2000) Age and cranial development of the South American fur seal, Arctocephalus australis (Zimmermann, 1783) (Carnivora: Otariidae) in the coast of Rio Grande do Sul, Brazil. Master Thesis. Fundação Universidade Federal do Rio Grande (FURG). Rio Grande, RS, Brazil. 117pp.

Molina, D.M. and Oporto, J.A. (1993) Comparative study of dentine staining techniques to estimate age in the Chilean dolphin, Cephalorhynchus eutropia (Gray, 1846). Aquatic Mammals 19 (1):45-48.

Molina, D.M. and Reyes, J.C. (1996) Determinación de edad en el delfín chileno Cephalorhynchus eutropia (Cetacea: Delphinidae). Revista Chilena de Historia Natural 69: 183-191.
Myrick, A.C.JR., Hohn, A.A., Sloan, P.A., Kimura, M. and Stanley, D.D. (1983) Estimating age of spotted and spinner dolphins (Stenella atennuata and Stenella longirostris). NOAA Technical Memorandum National Marine Fisheries Service Southwest Fisheries Center 30: 1-7.

Odell, D.K. (1975) Breeding biology of the California sea lion (Zalophus californianus). Repports et procès-verbeaux des Réunions Conscil International pour l' Exploration de la Mer. 169: 374-78.

Oliveira, L.R., Malabarba, L.R. and Majluf, P. (1999) Variação geográfica em crânios do lobo-marinho sulamericano Arctocephalus australis (Zimmermann, 1783) das populações do Brasil e Peru. Comunicações do Museu de Ciência e Tecnologia, Série Zoologia. PUCRS, 12: 179-192.

Oosthuizen, W.H. (1997) Evaluation of an effective method to estimate age of cape fur seal using ground tooth sections. Marine Mammal Science 13(4): 683-693.

Páez, E.A. (1989) Estudio del crecimiento en medidas craneales del lobo fino sudamericano, Arctocephalus australis (Zimmermann, 1783). Lic. Thesis, Universidad de la República. iii, 93pp.

Payne, M.R. (1978) Population size and age determination in the Antartic fur seal Arctocephalus gazella. Mammal Rev. 8: 67-73.

Perrin, W.F. and Myrick, A.C. Jr. (Eds) (1980). Age Determination of Toothed Whales and Sirenians. Reports of the International Whaling Commission (Special Issue 3).

Pierce, K.V. and Kajimura, H. (1980) Acid etching and highlighting for defining growth layers in cetacean teeth. Pages 99-103 in Perrin, W.P. and Myrick, A.C. (Eds) Age Determination of Toothed Whales and Sirenians. Reports of the International Whaling Commission (Special Issue 3).

Pinedo, M.C. and Hohn, A.A. (2000) Growth layer patterns in teeth from the franciscana, Pontoporia blainvillei: developing a model for precision in age estimation. Marine Mammal Science, 16(1): 1-27.

Reijnders, P., Brasseur, S., van der Toorn, J., van der Wolf, P., Boyd, I., Harwood, J., Lavigne, D. and Lowry, L. (1993) Seals, Furs Seals, Sea Lion, and Walrus. Status survey and conservation Action Plan. 88pp.

Rosas, F.C.W. (1989) Aspectos da dinâmica populacional e interações com a pesca, do leão marinho do sul, Otaria flavescens (Shaw, 1800) (Pinnipedia, Otariidae), no litoral sul do Rio Grande do Sul, Brasil. Master Thesis. Fundação Universidade Federal do Rio Grande (FURG). Rio Grande, RS, Brazil. 88pp.

Rosas, F.C.W., Haimovici, M. and Pinedo, M.C. (1993) Age and growth of the South American sea lion, Otaria flavescens (Shaw, 1800), in southern Brazil. Journal of Mammalogy 74(1): 141-147.

Scheffer, V.B. (1950) Growth layers on the teeth of Pinnipedia as an indication of age. Science 112: 309-311.

Scheffer, V.B. and Myrick, A.C. (1980) A review of studies to 1970 of growth layers in the teeth of marine mammals. Pages 51-63 in Perrin, W.P. and Myrick, A. C. (Eds) Age Determination of Toothed Whales and Sirenians. Reports of the International Whaling Commission (Special Issue 3).

Schiavini, A.C., Lima, M. and Batallés, L.M. (1988) Técnicas para la estimación de la edad en el lobo fino Sudamericano, Arctocephalus australis (Zimmermann, 1783). Documentos Técnicos Industria Lobera y Pesquera del Estado 1(1): 1-6. 
Schiavini, A.C.M., Lima, M. and Batallés, L.M. (1992) Growth structures of maxillary canines of the Southern fur seal (Arctocephalus australis). Marine Mammals Science 8(1): 89-93.

Stewart, R.E.A., Stewart, B.E., Stirling, I. and Street, E. (1996) Counts of growth layers and dentine in ringed seals (Phoca hispida). Marine Mammal Science 12(3): 383-401.
Yagi, T., Nishiwaki, M. and Nakajama, M. (1963). A preliminary study on the method of time marking with lead salt and tetracycline on the teeth of fur seal. Science Report Whales Research Institute, Tokyo 17: 191-195, 3pp.

Zar, J.H. (1984) Biostatistical Analysis. Prentice-Hall Inc. New Jersey, EUA. 718pp. 